\title{
Statistical Analysis of Factors Affecting Poverty Status of Rural Residence
}

\author{
Bereket Getachew Mamo*, Markos Abiso \\ Department of Statistics, Arba Minch University, Arba Minch, Ethiopia \\ Email address: \\ bereket_g@yahoo.com (B. G. Mamo) \\ ${ }^{*}$ Corresponding author
}

To cite this article:

Bereket Getachew Mamo, Markos Abiso. Statistical Analysis of Factors Affecting Poverty Status of Rural Residence. American Journal of Theoretical and Applied Statistics. Vol. 7, No. 5, 2018, pp. 188-192. doi: 10.11648/j.ajtas.20180705.14

Received: July 5, 2018; Accepted: August 6, 2018; Published: September 21, 2018

\begin{abstract}
Poverty is one of the serious problem affect the life of peoples in third world countries. Identifying major factors affecting poverty status of a society is important to decide what action should be taken to alleviate the poverty. The aim of this paper is to assess the factors that affect the poverty status of rural Residence in the study area. A cross-sectional study was conducted in five districts of Gamo Gofa zone, Southern Regional State of Ethiopia. From a total of households in these areas, 4092 were selected using stratified random sampling technique. Data were collected with a well designed questionnaire. If the welfare of a household is below the poverty line, the household is categorized as under poverty and if it is above poverty line, then the household is above poverty. Binary logistic regression model was used to analyze the data using the SPSS software. Several risk factors were found to be significant at the level of 5\%. Saving culture, access to credit, resource base, land fertility, use of agricultural inputs, use of improved tools, availability of rain, land topography, labor availability and dependency attitude have significant association with the poverty status of a households. Governments and Non-Governmental organization should be aware of the consequences of these factors which can influence the household income and future poverty status.
\end{abstract}

Keywords: Poverty, Household, Logistic Regression, Poverty Status and Poverty Factors

\section{Introduction}

Poverty is one of the major problems in the world. It is very serious in the third world like Ethiopia that needs a crucial attention. Thus, "Eradication of extreme poverty and hunger" was set to be the first priority of Millennium Development Goal (MDG). It was targeted to reduce by half the proportion of people whose income is less than \$US1 per day between 1990 and 2015. In 2000, the World Leaders were committed themselves to the Millennium Development Goals (MDGs) [1]. The proportion of people living with poverty in Sub-Saharan Africa is the highest one in the world, which is followed by Southern Asia. UN (2007) reported that the MDG was only achieved the reduction of the proportion of people living in extreme poverty in 2004 from $46.8 \%$ to $41.1 \%$ in Sub Saharan Africa. The poverty gap ratio fell from $19.5 \%$ to $17.5 \%$. Majority of Ethiopian People, as it is in Sub Sahara, are categorized with the poorest nations in the World.
The Human Development Report (HDR) reported that over $80 \%$ of the population survives on less than SUS 2 per day [2]. The most recent World Development Report of 2007 calculated a per capita income of US\$ 160 for Ethiopia and in the Human Development Index (HDI) Ethiopia was ranked $170^{\text {th }}$ out of 177 nations with HDI value of $0.371[3,4]$. The studies by $[5,6]$ reported that between 35 to $50 \%$ of the population was found to be poor. Previous studies of poverty in Ethiopia have generally focused on rural rather than urban areas [7-9]. This is due to the fact that around $85 \%$ of the population lives in rural areas. In addition to this, unfavorable weather fluctuations may take a heavy toll on the lives of rural farmers and bring them to the brink of starvation. This made rural famine prevention and poverty reduction a priority of both governmental and nongovernmental agencies. However; there was a study on urban area of the country by which showed that poverty in urban Ethiopia was quite high with an overall head count index of $47.2 \%$ in 1994 and $40.4 \%$ in 2000 using the additively decomposable FGT measures [10]. The cities of Mekelle, 
Hawassa and Dessie were the poorest in 1994 whereas Dire Dawa and Bahir Dar were the least poor. Between 1994 and 2000, the poverty situation in Hawassa and Mekelle were significantly improved while that in Dire Dawait was worsened. The improvements in Addis Ababa and Bahir Dar were also quite remarkable.

The study by [11] revealed that nearly $40 \%$ of the sampled households from three rural districts of Ethiopia (Alemaya, Hitosa and Merhabete) were living below poverty line with an average poverty gap of 0.047 . According to the researcher, the areas were purposively selected to represent major farming systems in Ethiopia. The finding by [12] was also indicated that the incidence of rural poverty is high for villages that have lower conditions for agriculture. The comparison study between rural and urban poverty using the 1994 rounds of the ERHS and EUHS by deriving different poverty lines was made, since household needs, prices and tastes across rural and urban area is different [6]. The Cost of Basic Needs Approach described in Ravallion and Bidani [13] was used by them in estimating the poverty lines. Their findings suggested that urban poverty was much higher than rural poverty when region specific food baskets were used. The government's 2004/2005 Household income and Consumption Expenditure Survey indicated that the incidence of poverty was higher in rural compared to urban areas with the poverty head count ratio being $39.3 \%$ and $35.1 \%$ respectively [14].

There are no detail studies on poverty at a regional level in SNNPR, especially in Gamo- Gofa zone in order to address the poverty status and determinant factors. To achieve MDGs, decreasing poverty by half in 2015, identifying causes and determinants of poverty in rural areas of a country is very important. Identifying and determining poverty factors can be used as source of information for further studies and will help police maker to set an appropriate measurement towards poverty reduction. Thus, this study was tried to identify the major factors affecting poverty status of rural residences of the study area in Gamo Gofa Zone in SNNPR part of Ethiopia.

The economic development of a country depends on poverty status of its people. The welfare of a society can be affected by different factors. These factors make hard for them to fulfill their basic needs. Identifying major factors affecting poverty status of a society is important to decide what action should be taken to alleviate the poverty. The main goal of the study is to assess factors that affect the poverty status of rural Residence in the study area.

\section{Methods}

The study conducted in the Gamo-Gofa Zone, Southern Nations, Nationalities and people region of Ethiopia. A crossSectional survey was conducted with a stratified sampling technique on 4092 samples from the total population of 99,132. Data were collected using well designed questionnaire which contain information on demographic factors, socio-economic variables, agricultural resource and technology use.

The response variable of the study was poverty status of a household. If the welfare of a household is below the poverty line, the household is categorized as under poverty and if it is above poverty line, then the household is above poverty. The explanatory variables, such as Sex of households head, Age of household head, Number of household members in Adult equivalent (AE), Age dependency ratio, marital form, Educational status of the head were considered as variables of Household Characteristics. Socio-economic Variables (Participation and active membership in different institution, saving habit of household, Access to credit, Poor resource base), Health factors (Health care facility and Distance from health care center). Economic and agricultural factors (Land owned by household, Size of cultivated land, Land fertility, Farm product price, Price of inputs, Household labor availability, Total livestock ( in TLU), Total non-farm income, Distance from nearest market), Other (Farmer attitude of dependency, Technology adoption, Availability of rain (water), and Land topography),

\section{Logistic Regression Model}

The response variable is poverty status of the residents, denoted by $\mathrm{Y}$, which is dichotomous with outcome either below poverty $(\mathrm{y}=1)$ with probability $\pi_{i}=p\left(Y_{i}=1 \mid X\right)$ or above poverty $(\mathrm{y}=0)$ with probabilityl $-\pi_{i}=p\left(Y_{i}=0 \mid X\right)$. The conditional probability that a household head $\mathrm{i}$ is below poverty (success) given the $\mathrm{X}_{\mathrm{i}}$ set of predictor variables is denoted by $\pi_{i}=$ prob $\left(\mathrm{Y}_{\mathrm{i}} \backslash \mathrm{X}_{\mathrm{i}}\right)$. The logistic regression model is given as: [15]

$$
\pi_{i}=\frac{e^{\beta_{0}+\beta_{1} x_{i 1}+\beta_{2} x_{i 2}+\ldots \beta_{p} x_{i p}}}{1+e^{\beta_{o}+\beta_{1} x_{i 1}+\beta_{2} x_{i 2} \ldots+\beta_{p} x_{i p}}}
$$

and equivalently expressed with the logit link function as

$$
\log i t\left(\pi_{i}\right)=\beta_{\mathrm{o}}+\beta_{1} \mathrm{X}_{\mathrm{i} 1}+\beta_{2} \mathrm{X}_{\mathrm{i} 2}+\ldots+\beta_{\mathrm{p}} \mathrm{X}_{\mathrm{ip}}
$$

where $i=1,2,3, \cdots n, j=0,1,2, \cdots p, X_{i j}$, the $j^{\text {th }}$ Predictors of $i^{\text {th }}$ households, $\beta_{0}$ is an intercept $\beta_{\mathrm{j}}$ 's are coefficients of the predictors variable

The likelihood function $L(Y \mid \mathrm{X}, \beta)$ is defined as the joint probability distribution $f(\mathrm{y} \mid \mathrm{X}, \beta)$ of the independent observation 
vector of size $n$ given the regression parameters $\beta$ and the design matrix X. The likelihood function with the $n$ independent observations is expressed as:

$$
L(Y \mid X, \beta)=\prod_{i=1}^{n}\left(\frac{e^{\beta_{0}+\beta_{1} x_{i 1}+\beta_{2} x_{i 2}+\ldots \beta_{\mathrm{p}} x_{i p}}}{1+e^{\beta_{o}+\beta_{1} x_{11}+\beta_{2} x_{i 2} \ldots+\beta_{p} x_{i p}}}\right)^{y_{i}}\left(\frac{1}{1+e^{\beta_{o}+\beta_{1} x_{i 1}+\beta_{2} x_{i 2} \ldots+\beta_{p} x_{i p}}}\right)^{1-y_{i}}
$$

It refers to how likely a particular population is to produce an observed sample given the parameter values. The estimation of parameters is based on the maximum likelihood method, with Newton-Raphson iterative search algorithm to maximize the likelihood function or its logarithmic transformation [15]

\section{Result and Discussion}

\subsection{Descriptive Statistics Result}

The descriptive statistics shows minimum and maximum number of household was 1 and 12 (0.80 and 10.9 in adult equivalent scale (AES) respectively and the average number of household was 5.7397 (4.7975 in AES) with standard deviation of 2.21 (1.811 in AES); the average dependency ratio of households was 691.04 . The average land owned by a household in the zone was 1.7946 hector. The average number of livestock in tropical livestock unit was 4.0970. The result of the descriptive statistics also showed the proportion population of households under poverty was $36.7 \%$. The cross tabulation result given in table 1 showed association and the proportion of each predictor variable against the response variable using test statistics Chi-square and likelihood ratio. Accordingly the household that had saving culture been $62.4 \%$, but $37.6 \%$ didn't. $34.7 \%$ of the household had access to credit while $65.4 \%$ didn't. The household that has dependency attitude was $81.0 \%$. The data revealed that only $61.7 \%$ and $10.6 \%$ use agricultural inputs and improved tools respectively. $15.6 \%$ respondents had a good resource base from their family.

The result from Table 1 showed that there was significant association between response variable poverty status and explanatory variables such as saving culture, access to credit, resource base, land fertility, use agricultural inputs, use of improved tools, availability of rain, land topography, labor available, and dependency attitude. Whereas the other response variables like access to market didn't have significance association with response variable.

Table 1. The Association between Poverty Status Vs Predictor Variables.

\begin{tabular}{|c|c|c|c|c|c|c|c|c|c|}
\hline \multirow{2}{*}{ Variable } & \multirow{2}{*}{ Category } & \multicolumn{2}{|c|}{ Above poverty } & \multicolumn{2}{|c|}{ Under poverty } & \multicolumn{2}{|l|}{ Total } & \multirow{2}{*}{ Chi-square (sig.) } & \multirow{2}{*}{ Likelihood Ratio (sig.) } \\
\hline & & count & $\%$ & count & $\%$ & count & $\%$ & & \\
\hline Saving culture & Yes & 1424 & 55.0 & 1131 & 75.3 & 2555 & 62.4 & $168.486(0.000)$ & $73.929(0.000)$ \\
\hline \multirow{2}{*}{ Access to credit } & Yes & 664 & 25.6 & 757 & 50.4 & 1421 & 34.7 & \multirow{2}{*}{$258.00(0.000)$} & \multirow{2}{*}{$254.802(0.000)$} \\
\hline & No & 1927 & 74.4 & 744 & 49.6 & 2671 & 65.3 & & \\
\hline Access to market & Yes & 509 & 19.6 & 301 & 20.1 & 810 & 19.8 & $0.100(0.752)$ & $0.100(0.783)$ \\
\hline \multirow{2}{*}{ Resource base } & Yes & 522 & 20.1 & 118 & 7.9 & 640 & 15.6 & \multirow{2}{*}{$108.72(0.000)$} & \multirow{2}{*}{$118.791(0.000)$} \\
\hline & No & 2069 & 79.9 & 1383 & 92.1 & 3452 & 84.4 & & \\
\hline \multirow{2}{*}{ Land fertility } & Yes & 761 & 29.4 & 396 & 26.4 & 1157 & 28.3 & \multirow{2}{*}{$4.185(0.041)$} & \multirow{2}{*}{$4.211(0.040)$} \\
\hline & No & 1830 & 70.6 & 1105 & 73.6 & 2935 & 71.7 & & \\
\hline \multirow{2}{*}{ Use agricultural inputs } & Yes & 1905 & 73.5 & 619 & 41.2 & 2524 & 61.7 & \multirow{2}{*}{$419.12(0.000)$} & \multirow{2}{*}{$417.69(0.000)$} \\
\hline & No & 686 & 26.5 & 882 & 58.8 & 1568 & 38.3 & & \\
\hline Use of improved tools & No & 2217 & 85.6 & 1439 & 95.9 & 3656 & 89.4 & $105.00(0.000)$ & $119.56(0.000)$ \\
\hline \multirow{3}{*}{ Availability of rain } & Little & 1069 & 41.3 & 295 & 19.7 & 1364 & 33.3 & \multirow{3}{*}{$200.0(0.000)$} & \\
\hline & Enough & 825 & 31.8 & 678 & 45.2 & 1503 & 36.7 & & $210.0(0.000)$ \\
\hline & Too much & 697 & 26.9 & 528 & 35.2 & 1225 & 29.9 & & \\
\hline & Plain & 1352 & 52.2 & 827 & 55.1 & 2179 & 53.3 & & \\
\hline Land topography & Hilly & 1066 & 41.2 & 644 & 42.9 & 1710 & 41.8 & $43.66(0.000)$ & $49.86(0.000)$ \\
\hline & Steep & 172 & 6.6 & 30 & 2.0 & 202 & 4.9 & & \\
\hline I por oupiloth & Yes & 1261 & 48.7 & 877 & 58.4 & 2138 & 52.2 & $26281(0000)$ & $26410(0000)$ \\
\hline Labor avallable & No & 1330 & 51.3 & 624 & 41.6 & 1954 & 47.8 & $36.281(0.000)$ & $36.410(0.000)$ \\
\hline Denendency attitude & Yes & 2130 & 82.2 & 1184 & 78.9 & 3314 & 81.0 & $6832(0.009)$ & $6759(0.009)$ \\
\hline Dependency atutude & No & 461 & 17.8 & 317 & 21.1 & 778 & 19.0 & $0.832(0.009)$ & $0.139(0.009)$ \\
\hline Access to non-farm & Yes & 972 & 37.5 & 394 & 26.2 & 1366 & 33.4 & $54237(0000)$ & $55304(0000)$ \\
\hline employment & No & 1619 & 62.5 & 1107 & 73.8 & 74 & 66.6 & $34.25 /(0.000)$ & $53.504(0.000)$ \\
\hline
\end{tabular}




\subsection{Multiple Logistic Regression Analysis Result}

Before discussing the result obtaining from the model, the adequacy of the model should be cheeked or assessed. Likelihood ratio (LR) tests, $\mathrm{R}^{2-}$ statistics, Hosmer-Lemeshow test and classification table was used to check adequacy of the model

LR test is a test of the significance of the difference between the likelihood ratios for the researcher's model (final fitted model) and the likelihood ratio for a reduced model (null model).

The hypothesis to be tested to the overall fit of the model was:

$\mathrm{H}_{0}$ : The model is a good fitting to the data Vs. $\mathrm{H}_{1}$ : The model is not a good fitting to the data

The likelihood ratio test (deviance) was applied to test the difference between the null and the final model. The result from the analysis showed -2LogLikelihood value for null model and final model was 5213.724 and 3951.801 respectively. Model chi-square value was 1631.012 with 17 degree of freedom and the probability $p=0.000$. This indicates the final model was a good fit, which showed that the predictor variables had a significant effect at $5 \%$ levels of significances. From the Hosmer-Lemeshow test statistics analysis it was obtained the chi-square test statistic 7.220 with $0.513 \mathrm{p}$ - value. Therefore the model was quite a good fit, because p-valve exceeds 0.05 . There is no difference between the observed and predicted model value. Hence, the estimated model fit the data well.

Result from classification table $81.1 \%$ of the sample households which were included in the model was correctly predicted. The sensitivity was $84.6 \%$ and the specificity was $76.3 \%$ which indicated $76.5 \%$ of below poverty line and $84.6 \%$ of above poverty line were correctly predicted in their respective categories.

Table 2. Variable in the Final Multiple Logistic Regression Model.

\begin{tabular}{|c|c|c|c|c|c|c|}
\hline Predictors & Beta & S.E $(\widehat{\boldsymbol{\beta}})$ & Wald & df & Sig. & $\operatorname{Exp}^{\prime}(\widehat{\beta})$ \\
\hline Constant & -0.655 & .552 & 43.859 & 1 & .000 & .026 \\
\hline Dependency ratio & .004 & .001 & 36.214 & 1 & .000 & 1.004 \\
\hline $\mathrm{HH}$ size in AES & .613 & .031 & 400.340 & 1 & .000 & 1.846 \\
\hline Saving culture & .415 & .097 & 18.434 & 1 & .000 & 1.514 \\
\hline Access to credit & .438 & .088 & 24.897 & 1 & .000 & 1.549 \\
\hline Resource base & .798 & .131 & 37.314 & 1 & .000 & 2.201 \\
\hline Dependency attitude & -.698 & .114 & 37.306 & 1 & .000 & .497 \\
\hline Land owned by household in hectar & -.247 & .032 & 58.681 & 1 & .000 & .781 \\
\hline land fertility & .017 & .112 & .023 & 1 & .879 & 1.017 \\
\hline Market access & .745 & .132 & 31.913 & 1 & .000 & 2.107 \\
\hline HH labor availability & .323 & .095 & 11.605 & 1 & .001 & 1.382 \\
\hline Number of livestock in TLU & -.147 & .016 & 84.792 & 1 & .000 & .863 \\
\hline Use of agricultural inputs & 1.384 & .095 & 212.068 & 1 & .000 & 3.990 \\
\hline Use of improved tools & .469 & .181 & 6.752 & 1 & .009 & 1.598 \\
\hline
\end{tabular}

The result in Table 2 showed the output for logistic regression model. The odds ratio of household size implies that, as the household size increases by one AES unit, the odds of a household being under poverty increased by $84.6 \%$. From the odds ratio of household dependency ratio it can be observed that as the dependency ratio increased by one unit, the odds of being under poverty decreased by $0.4 \%$. Household that had no saving culture was 1.514 times more likely to be under poverty than those households that had saving culture. It means that the odds of a household being under poverty increased by $51.4 \%$. Households that had access to credit were also 0.549 times less likely to be under poverty than those households that did not have the access. It mean that household with no access to credit, their odds of being under poverty was increased by $54.9 \%$. Households with no resource base were 2.201 times more likely to be under poverty than those with good resource base. That is their odds of being under poverty increased by $120.1 \%$. Dependency attitude of the household was also one of the significant predictor variables. Its odds ratio indicated that the odds of households with no dependency attitude was 0.497 times less likely to be under poverty than the reference group (those with dependency attitude). As a land owned by a household increased by one hector, the odds of being under poverty decreased by $21.9 \%$. This told us that as the land size owned by a household increased, the risk of a household being under poverty decreases. The result also showed that for those the households who used agricultural inputs and improved tool, the risk their being under poverty was decreased.

Result of the logistic regression model discussed above the household size was found to be a significant determinant of poverty. This result is consistent with the findings [16-18].

The predictor variables saving culture and access to credit were found to be significant poverty factors. Saving culture helps a household to reduce unnecessary expenditure and wastage. Access to credit can also help a household to generate additional income. Hence, these help a household to escape out from poverty. The result is consistent with [19].

Household's resource base and dependency attitude were also found to be significant poverty factors of the study area. Land owned by household reduces the risk of being under poverty. This is due to the fact that households that have larger land have a chance of escaping from being under poverty (as they can get more products from it). The result is consistent with the findings $[17,18,20]$. 


\section{Conclusion}

Based on the collected data from the study area, proportion of households under poverty was $36.7 \%$. From bivariate analysis: Saving culture, access to credit, resource base, land fertility, use of agricultural inputs, use of improved tools, availability of rain, land topography, labor availability and dependency attitude have significant association with the poverty status of a households. The result of logistic regression showed that variables: dependency ratio, household size in AES, saving culture, access to credit, resource base, dependency attitude, land owned by household in hector, use of improved tools, household labor availability, number of livestock in TLU, use of agricultural inputs and market access have significant effect on the poverty status of household of in the study area based on the collated data from the study area. Based on identified factors, the researchers recommend that awareness on saving culture should be created for households under poverty; dependency attitude of the household should be changed by concerned bodies. The use of improved tools and agricultural inputs decreases likelihood of a household being under poverty, the farmer should be encouraged using them. Households should have a good market access for their product.

\section{References}

[1] UN (2007). The Millennium Development Goals Report. United Nations Department of Economic and Social Affairs DESA.

[2] UNDP (2005). Human Development Report 2005. Oxford University Press. New York.

[3] World Bank (2007). Development and the Next Generation. World Development Report 2007. World Bank, Washington, DC.

[4] UNDP (2006). Beyond Scarcity: Power, Poverty, and the Global Water Crisis. Human Development Report 2006. Palgrave Macmillan, New York.

[5] Bigsten, A. and S. Abebe (2003): The Dynamics of Poverty in Ethiopia. Paper Prepared for a WIDER Conference on Inequality, Poverty and Human Well-Being. Department of Economics, University of Gothenburg, Sweeny.

[6] Tadesse, M. (1999). Determinants and Dynamics of Urban Poverty in Ethiopia. Ethiopian Journal of Economics, 8 (1):61-82.
[7] Dercon, S., P. Krishnan (1998). Changes in Poverty in Rural Ethiopia 1989-956: Measurement, Robustness test and Decomposition. Working Paper Series 98-7. University of Oxford: Centre for the Study of African Economies.

[8] Dercon, S., J. Hoddinott and Tassew Woldehanna (2007). Growth and Poverty in Rural Ethiopia: Evidence from 15 Communities 1994-2004. Background Paper for the Chronic Poverty Report 2008-09.

[9] Ayalneh, B., H. Konrad, and K. Benedikt (2003). Why Does Poverty Persist in Rural Ethiopia? Alemaya University, Ethiopia

[10] Tesfaye, A. (2006). "The Analysis of Urban Poverty in Ethiopia." University of Sydney, Australia.

[11] Ayalneh, B., H. Konrad, and K. Benedikt (2005). Determinants of Poverty in Rural Ethiopia. Quarterly Journal of International Agriculture, 44 (2):101-120.

[12] Mohammad, S. (2009). The Analysis of Rural Poverty in Ethiopia. Uppsala University Department of Economics. Master Thesis. Spring.

[13] Ravallion, M. and B. Bidani (1994). How Robust is a Poverty Profile? The World Bank Economic Review, 8 (1):75-102.

[14] MoFED (2006). Ethiopia: Building on Progress - A Plan for Accelerated and Sustained Development to End Poverty (PASDEP) (2005/06-2009/10). Volume I. Main Text, Addis Ababa.

[15] Agresti A. An Introduction to Categorical Data Analysis. 3rd ed. New York: John Wiley and Sons Inc.; 1996.

[16] Hassan, M. Rashid and Babu, C. Suresh (1991). Measurement and Determinants of Rural Food Poverty. Food Policy.

[17] Dercon, S. and P. Krishnan (1996). A Consumption-Based Measure of Poverty for Rural Ethiopia in 1989 and 1994. In Bereket K. and Mokonen T. (Eds.). The Ethiopian Economy: Poverty and Poverty Alleviation. Proceedings of the Fifth Annual Conference on the Ethiopian Economy. Addis Ababa.

[18] MoFED (2002). Development and Poverty Profile of Ethiopia. Ministry of Finance and Economic Development (MoFED). Addis Ababa.

[19] Metalign A. T. (2005). Rural Poverty Situation and Determinants: The Case of Kersa Kondaltity Woreda, South West Shewa. M.Sc. Thesis. Addis Abeba University.

[20] World Bank (1998). Participatory Poverty Assessment for Ethiopia. World Bank Discussion Paper, African Region. 